American Journal of Animal and Veterinary Sciences 5 (4): 233-236, 2010

ISSN 1557-4555

(C) 2010 Science Publications

\title{
Effects of Metabolite Combinations Produced by Lactobacillus plantarum on Plasma Cholesterol and Fatty Acids in Piglets
}

\author{
${ }^{1}$ T.V. Thu, ${ }^{1}$ Loh Teck Chwen, ${ }^{2}$ H.L. Foo, ${ }^{1}$ Y. Halimatun and ${ }^{3}$ M.H. Bejo \\ ${ }^{1}$ Department of Animal Science, Faculty of Agriculture \\ ${ }^{2}$ Department of Bioprocess Technology, Faculty of Biotechnology and Biomolecular Science, \\ ${ }^{3}$ Department of Veterinary Pathology, Faculty of Veterinary Medicine \\ University Putra Malaysia, 43400 UPM Serdang, Selangor, Malaysia
}

\begin{abstract}
Problem statement: Hypercholesterol and fatty acids in plasma are the main causes for cardiovascular disease. Reduction of risk factors from diet that associated with cardiovascular disease has much attention in animals as well as in human. The objective of this study was to investigate the effects of feeding liquid metabolite combinations produced by five L. plantarum strains on the fatty acids and cholesterol concentration in plasma of postweaning piglets. Approach: A total of 120 postweaning piglets aged 26 day olds (Large White $\mathrm{x}$ Landrace $\mathrm{x}$ Duroc) were randomly assigned into one of five treatments. (i) basal diet with free antibiotic (-ve control); (ii) basal diet with $0.03 \%$ of chlortetracycline antibiotic (+ve control); (iii) basal diet with $0.3 \%$ metabolite of TL1, RG11 and RI11 (Com 1); (iv) basal diet with 0.3\% metabolite of TL1, RG14 and RS5 (Com 2); (v) basal diet with $0.3 \%$ metabolite of RG11, RG14 and RI11 (Com 3). The experiment was conducted for 5 weeks. Fatty acids were analysed by Gas Chromatography (GC) and cholesterol was detected using commercial diagnostic kit. Results: The piglets fed with metabolite combinations were found to reduce plasma cholesterol and Saturated Fatty Acids (SFA) concentrations, particularly in Com 2 group which was significantly lower $(\mathrm{p}<0.05)$ than the -ve control group. In contrast, the Unsaturated Fatty Acids (USFA) were significantly higher $(\mathrm{p}<0.05)$ in Com 2 than -ve control group. The ratio of USFA and SFA was significantly higher (1.14\%) in Com 2 as compared to -ve control group. However, there was significantly lower $(\mathrm{p}<0.05)$ in Com 3 as compared to control groups for the ratio of omega- 6 and omega-3 in plasma of piglets. Conclusion: Metabolite combinations produced by L. plantarum strains have potential effects in influencing the lipid contents and reducing the cholesterol profile of the pig's plasma.
\end{abstract}

Key words: Cholesterol, fatty acids, postweaning piglets, Lactobacillus plantarum, metabolite combination, hypercholesterol

\section{INTRODUCTION}

Cardiovascular disease is one of the public health concerns as it has affected millions of people in developed countries and alarming those from the developing countries. Hypercholesterol and fatty acids in plasma are the main causes for cardiovascular disease (Talon et al., 2000; Niu et al., 2007). Sindhu and Khetarpaul (2003) reported that $1 \%$ reduction in plasma cholesterol was associated with reductions of $2-3 \%$ in the risk of coronary artery disease. Therefore, reduction of risk factors from diet which associated with cardiovascular disease has much attention in human as well as in animals. It has been reported that LAB able to reduce plasma cholesterol when used as an additive in animal feeding (Sindhu and Khetarpaul, 2003; Loh et al., 2009). Lee et al. (2009) showed Lactobacillus plantarum could reduce the plasma cholesterol. Foo et al. (2003) also reported that Lactobacillus cultures from fermented products decreased plasma cholesterol concentration in rats. Recently, metabolites of LAB containing lactic, acetic, propionic, butyric acids, ethanol and bacteriocins were able to increase faecal $\mathrm{LAB}$, volatile fatty acids and decrease faecal $\mathrm{pH}$, plasma cholesterol in rats and chickens (Foo et al., 2005; Thanh et al., 2009). Moreover, Loh et al. (2009) reported that feeding of spray-dried metabolites from L. plantarum reduced plasma cholesterol and increased essential fatty acids in rats. However, the effects of feeding metabolites on plasma

Corresponding Author: Loh Teck Chwen, Department of Animal Science, Faculty of Agriculture, University Putra Malaysia, 43400 UPM Serdang, Selangor, Malaysia Tel: +603 89466899 Fax: +603 89432954 
cholesterol and fatty acid concentrations in piglets are still unknown yet. Thus, the objectives of this study was to determine the effects of liquid metabolite combinations produced by $L$. plantarum on total plasma cholesterol and fatty acid concentrations of postweaning piglets.

\section{MATERIALS AND METHODS}

Preparation of metabolites: The metabolites were produced from the strains of $L$. plantarum namely TL1, RG11 RG14, RS5 and RI11. The L. plantarum strains were isolated from Malaysian fermented foods and kept at $-20^{\circ} \mathrm{C}$ in Man Rogosa Sharpe broth (MRS; Merck, Darmstadt, Germany) with 20\% (v/v) glycerol. The stock culture has revived twice in MRS broth and incubated anaerobic condition for $48 \mathrm{~h}$ at $30^{\circ} \mathrm{C}$. After streaked on MRS agar, a single colony was picked and subcultured twice in MRS broth. The liquid metabolites were prepared according to the method as described by Foo et al. (2003). Metabolites were harvested by separating the cell free supernatant (CFS) with centrifugation at $12000 \mathrm{rpm}$ for $15 \mathrm{~min}$ at $4^{\circ} \mathrm{C}$. The combinations were mixed by equal volume from each strain before being fed to piglets in their diets. The metabolite combinations were used in this experiment trial with lactic acid concentrations: Com $1\left(3.65 \mathrm{~g} \mathrm{~L}^{-1}\right)$, Com $2\left(3.81 \mathrm{~g} \mathrm{~L}^{-1}\right)$ and Com $3\left(3.43 \mathrm{~g} \mathrm{~L}^{-1}\right)$; acetic acid concentrations: Com $1\left(1.13 \mathrm{~g} \mathrm{~L}^{-1}\right)$, Com $2\left(1.18 \mathrm{~g} \mathrm{~L}^{-1}\right)$ and Com $3\left(1.18 \mathrm{~g} \mathrm{~L}^{-1}\right)$. Bacteriocin activity of three metabolite combinations against Pediococcus acidilactici was $1600 \mathrm{Au} \mathrm{mL}^{-1}$.

Animals and diets: This experiment was carried out at the Commercial Research Unit in a pig farm, Tanjung Sepat, Selangor, Malaysia. A total of 120 postweaning crossbred piglets (Large White $\times$ Landrace $\times$ Duroc) of 20 litters from 3rd-4th parity of sows, at 26 days of age with an average initial body weight (BW) of $6.32 \pm$ $0.14 \mathrm{~kg}$. The piglets were kept in raised slatted floor pens $(1.2 \times 1.6 \mathrm{~m})$ at temperature ranging from $26-32^{\circ} \mathrm{C}$ and the humidity was $86 \pm 4 \%$. Water and feed were offered ad libitum throughout the experimental period. The piglets were randomly assigned into one of five treatments using the same basal diet with $\mathrm{CP} 21.1 \%$ and ME 14.2 $\mathrm{MJ} \mathrm{kg}^{-1}$ DM. Five treatments were: (1) -ve control (free antibiotic); (2) +ve control $(0.03 \%$ antibiotic of chlortetracycline); (3) Com 1 ( $0.3 \%$ metabolite of TL1, RG11 and RI11 strains); (4) Com 2 (0.3\% metabolite of TL1, RG14 and RS5 strains); (5) Com 3 (0.3\% metabolite of RG11, RG14 and RI11 strains). The trial was investigated for five consecutive weeks. At the end of experimental period, three piglets with similar body weight in each treatment were fasted for $12 \mathrm{~h}$ and sacrificed for blood samples collection.

Cholesterol and fatty acids measurement: Blood samples were collected from jugular vein of piglets and kept in vacutainer tubes containing EDTA (Becton Dickinson, New Jersey, USA). The plasma was then collected after centrifugation at $12000 \mathrm{rpm}$ for $20 \mathrm{~min}$. The cholesterol concentration was measured by enzymatic method using the cholesterol diagnostic kit (Randox Laboratories Ltd, UK). This procedure was based on the method as described by Loh et al. (2009). The determination method of fatty acids was modified from Oliveira et al. (2009). The plasma was mixed with chloroform-methanol and flushed by nitrogen before filtered through Whatman paper to collect liquid solution. The sample solution was continually extracted by several procedures to harvest fatty acid methyl esters and kept at $4^{\circ} \mathrm{C}$ until further analysis using gas chromatography.

Statistical analyses: Data were analysed by one-way analysis of variance and presented as the mean \pm standard error of the mean (SEM). The effects of dietary treatments were tested using the General Linear Model procedure of SAS 1998 (SAS Inst., Inc., Cary, NC). Duncan's Multiple Range Test System was used to compare the significant difference at $\mathrm{p}<0.05$.

\section{RESULTS}

Plasma cholesterol concentration of pigs fed with different dietary treatments is presented in Table 1 . The results showed that cholesterol concentration was significantly lower $(\mathrm{p}<0.05)$ in Com 2 as compared to those in -ve control. However, no significant differences $(p>0.05)$ were found between metabolite treatments and +ve control group in this study.

Two types of fatty acids detected in plasma of piglets, i.e. Saturated Fatty Acids (SFA) and Unsaturated Fatty Acids (USFA). SFA comprises of caprylic, capric, lauric, myristic, palmitic, stearic acids, whereas USFA comprises of oleic, linoleic (n-6), alphalinolenic (n-3) and arachidonic acids (Table 1). The concentration of SFA in plasma when piglets fed with Com 2 was significantly lower $(\mathrm{p}<0.05)$ than those in ve control, particularly the caprylic acid. In contrast, USFA was significantly higher $(\mathrm{p}<0.05)$ in Com 2 than those in -ve control, particularly the oleic acid concentration. As a result, the ratio of USFA and SFA was also significantly higher (1.14\%) in Com 2 treatment when compared to -ve control. Feeding of metabolite Com 2 (TL1, RG14 and RS5 strains) for piglets found to be able to reduce total SFA concentrations in plasma. 
American J. Animal \& Vet. Sci., 5 (4): 233-236, 2010

Table 1: Cholesterol and fatty acids concentration in plasma of piglets fed with different dietary treatments

\begin{tabular}{|c|c|c|c|c|c|}
\hline \multirow[b]{2}{*}{ Parameters } & \multicolumn{3}{|c|}{ Dietary treatments } & \multirow[b]{2}{*}{ Com 2} & \multirow[b]{2}{*}{ Com 3} \\
\hline & -ve control & +ve control & Com 1 & & \\
\hline \multicolumn{6}{|c|}{ Plasma cholesterol $\left(\mathrm{mg} \mathrm{dL}^{-1}\right)$} \\
\hline & $195.05 \pm 22.0^{\mathrm{a}}$ & $182.53 \pm 19.1^{\mathrm{ab}}$ & $159.30 \pm 15.7^{\mathrm{ab}}$ & $134.18 \pm 8.6^{\mathrm{b}}$ & $183.05 \pm 12.1^{\mathrm{ab}}$ \\
\hline \multicolumn{6}{|c|}{ Plasma fatty acids (\%) } \\
\hline $\mathrm{C} 8: 0$ & $1.97 \pm 0.20^{\mathrm{ab}}$ & $1.21 \pm 0.61^{\mathrm{bc}}$ & $2.71 \pm 0.29^{\mathrm{a}}$ & $0.72 \pm 0.39^{c}$ & $1.63 \pm 0.10^{\mathrm{abc}}$ \\
\hline C10:0 & $5.35 \pm 1.32^{\mathrm{a}}$ & $3.32 \pm 0.04^{\mathrm{a}}$ & $5.61 \pm 1.67^{\mathrm{a}}$ & $2.31 \pm 0.15^{\mathrm{a}}$ & $2.84 \pm 0.45^{\mathrm{a}}$ \\
\hline C12:0 & $4.99 \pm 0.63^{\mathrm{a}}$ & $3.57 \pm 0.33^{\mathrm{a}}$ & $4.54 \pm 1.06^{\mathrm{a}}$ & $2.97 \pm 0.35^{\mathrm{a}}$ & $3.19 \pm 0.38^{\mathrm{a}}$ \\
\hline $\mathrm{C} 14: 0$ & $4.74 \pm 0.51^{\mathrm{a}}$ & $3.53 \pm 0.03^{\mathrm{a}}$ & $6.42 \pm 2.71^{\mathrm{a}}$ & $3.31 \pm 0.40^{\mathrm{a}}$ & $3.41 \pm 0.03^{\mathrm{a}}$ \\
\hline C16:0 & $22.91 \pm 0.78^{\mathrm{a}}$ & $23.87 \pm 1.19^{\mathrm{a}}$ & $22.01 \pm 0.20^{\mathrm{a}}$ & $22.42 \pm 1.10^{\mathrm{a}}$ & $23.38 \pm 0.49^{\mathrm{a}}$ \\
\hline C18:0 & $15.60 \pm 1.37^{\mathrm{a}}$ & $15.43 \pm 0.45^{\mathrm{a}}$ & $13.00 \pm 2.64^{\mathrm{a}}$ & $15.12 \pm 1.12^{\mathrm{a}}$ & $16.00 \pm 1.26^{\mathrm{a}}$ \\
\hline C18:1 & $12.82 \pm 0.93^{\mathrm{b}}$ & $17.02 \pm 0.63^{\text {ab }}$ & $16.41 \pm 3.22^{\mathrm{ab}}$ & $18.75 \pm 1.29^{\mathrm{a}}$ & $14.92 \pm 1.09^{\mathrm{ab}}$ \\
\hline C18:2 n-6 & $17.60 \pm 0.79^{\mathrm{a}}$ & $19.58 \pm 0.59^{\mathrm{a}}$ & $16.96 \pm 0.12^{\mathrm{a}}$ & $19.34 \pm 0.88^{\mathrm{a}}$ & $18.15 \pm 1.71^{\mathrm{a}}$ \\
\hline C18:3n-3 & $3.03 \pm 0.77^{\mathrm{b}}$ & $3.11 \pm 0.34^{\mathrm{b}}$ & $4.60 \pm 0.67^{\mathrm{b}}$ & $5.64 \pm 0.41^{\mathrm{ab}}$ & $7.50 \pm 1.43^{\mathrm{a}}$ \\
\hline C20:4 & $10.99 \pm 0.41^{\mathrm{a}}$ & $9.37 \pm 0.81^{\mathrm{a}}$ & $7.77 \pm 1.90^{\mathrm{a}}$ & $9.44 \pm 1.90^{\mathrm{a}}$ & $8.96 \pm 1.13^{\mathrm{a}}$ \\
\hline Total SFA & $55.58 \pm 2.15^{\mathrm{a}}$ & $50.94 \pm 1.08^{\mathrm{ab}}$ & $54.29 \pm 3.57^{\mathrm{a}}$ & $46.86 \pm 1.35^{\mathrm{b}}$ & $50.47 \pm 0.48^{\mathrm{ab}}$ \\
\hline Total USFA & $44.47 \pm 2.15^{\mathrm{b}}$ & $49.09 \pm 1.08^{\mathrm{ab}}$ & $45.74 \pm 3.56^{\mathrm{b}}$ & $53.17 \pm 1.36^{\mathrm{a}}$ & $49.53 \pm 0.48^{\mathrm{ab}}$ \\
\hline USFA: SFA & $0.80 \pm 0.06^{\mathrm{b}}$ & $0.96 \pm 0.04^{\mathrm{ab}}$ & $0.85 \pm 0.12^{\mathrm{b}}$ & $1.14 \pm 0.06^{\mathrm{a}}$ & $0.98 \pm .0 .02^{\mathrm{ab}}$ \\
\hline$n-6: n-3$ & $6.57 \pm 1.63^{\mathrm{a}}$ & $6.45 \pm 0.75^{\mathrm{a}}$ & $3.83 \pm 0.51^{\mathrm{ab}}$ & $3.44 \pm 0.11^{\mathrm{ab}}$ & $2.77 \pm 0.92^{\mathrm{b}}$ \\
\hline
\end{tabular}

However, total essential USFA increased in plasma of piglets fed with metabolite combination dietary treatments as compared to those in -ve control. In addition, a significant reduction $(\mathrm{p}<0.05)$ for the ratio of omega- 6 and omega- 3 in plasma was found when compared the Com 3 to both control groups after 5 weeks of experiment.

\section{DISCUSSION}

The result of this study indicates that total plasma cholesterol concentration of piglets was decreased after feeding with metabolite combinations produced by $L$. plantarum. This is complement with Loh et al. (2009) when they reported that feeding $0.25 \%$ spray-dried metabolite was able to reduce the plasma cholesterol concentration in postweaning rats. Fermented milk containing $L$. acidophilus $\mathrm{L} 1$ had effects in reducing 2.4-3.2\% of serum cholesterol concentration in human (Lee et al., 2009). The effect of LAB on lipid content may be due to enhance the bile salt hydrolase (BSH) activity and facilitate the elimination of cholesterol in faeces. Effects of Lactobacillus in the gut could slow down the absorption of cholesterol into body as well (Nguyen et al., 2007). Bacteriocin activity with BSH can reduce plasma cholesterol by increasing consequently in the synthesis of bile salts, decreasing the solubility of cholesterol and reducing its uptake in the gut (Sindhu and Khetarpaul, 2003; Liong and Shah, 2005; Ting et al., 2010). This is in agreement with Lee et al. (2009), who explained that cholesterol reduction by LAB may involve five mechanisms: (i)
LAB inhibit cholesterol synthesis enzymes and thus reduce cholesterol production; (ii) LAB facilitate the elimination of cholesterol in faeces; (iii) LAB inhibit the absorption of cholesterol back into the body by binding with cholesterol; (iv) LAB interfere with the recycling and enhancing the excretion of bile salts; (v) due to the assimilation of lactic acid. Thanh et al. (2009) also reported that feeding of metabolite combinations produced by Lactobacillus plantarum had lower plasma triacylglycerol and cholesterol ester in broiler chickens.

On the other hand, Biro and Biro (2006) showed that effects of LAB increased the essential USFA and decreased SFA in human plasma. Akinori et al. (2003) reported that LAB could produce Conjugated Linoleic Acid (CLA) during fermentation from ricinoleic acid, which is one of essential USFA relates to coronary artery disease. The current results also show the ratio of USFA and SFA in plasma piglets was increased when fed with $L$. plantarum metabolites, this is in contrast with the ratio of omega- 6 and omega- 3 in plasma of piglets. The results indicate that metabolites produced by $L$. plantarum has positive effects in plasma long chain fatty acids, particularly in omega- 3 , it is an important component for all cell membranes and development of retina, as well as brain (SanGiovanni and Chew, 2005; Pourahmad et al., 2009). They interfere with the absorption of fats, produce bacterial fatty acids to convert linoleic and oleic acids into stearic acid by biohydrogenation of the double bonds (Oliveira et al., 2009) and complex fat is broken down into easily assailable components (Lee et al., 2009). 


\section{CONCLUSION}

The L. plantarum metabolite is able to reduce the plasma cholesterol and increase the USFA and SFA ratio. The combination of metabolites from TL1, RG14 and RS5 strains offered the best effect on lipid profiles in the plasma of piglets.

\section{ACKNOWLEDGEMENT}

This study was supported by Research University Grant Scheme (RUGS), University Putra Malaysia.

\section{REFERENCES}

Akinori, A., O. Jun, K. Shigenobu and S. Sakayu, 2003. CLA production from ricinoleic acid by lactic acid bacteria. J. Am. Oil Chem. Soc., 80: 889-894. DOI: 10.1007/s1 1746-003-0790-1

Biro, J.C. and J.M.K. Biro, 2006. The meaning of a redundant codon: There is protein folding information in nucleic acids in addition to the genetic code. Am. J. Biochem. Biotechnol., 2: 9-18. http://www.scipub.org/fulltext/ajbb/ajbb219-18.pdf

Foo, H.L., T.C. Loh, F.L. Law, Y.Z. Lim, C.N. Kufli and G. Rusul, 2003. Effects of feeding L. plantarum I-UL4 isolated from Malaysian Tempeh on growth performance, faecal flora and lactic acid bacteria and plasma cholesterol concentrations in postweaning rats. Food Sci. Biotechnol., 4: 403-408. http://fsnb.or.kr/publication/popup_paper_view.php ?no $=336$

Foo, H.L., Y.S. Lim, T.C. Loh, N.M. Saleh, A.R. Raha and G. Rusul, 2005. Characterization of bacteriocin produced by $L$. plantarum I-UL4 isolated from Malaysian fermented tapioca, Tapai Ubi. Proceeding of the 4th NIZO Dairy Conference, (NIZOd'05) Papendal, Netherland, pp: 1-33.

Lee, D., S. Jang, E. Baek, M. Kim and K. Lee et al., 2009. Lactic acid bacteria affect serum cholesterol levels, harmful fecal enzyme activity and fecal water content. Lipids Health and Dis., 24: 1-8. DOI: 10.1186/1476-511X-8-21

Liong, M.T. and N.P. Shah, 2005. Acid and Bile Tolerance and cholesterol removal ability of Lactobacilli strains. J. Dairy Sci., 88: 55-66. DOI: 10.3168/jds.S0022-0302(05)72662-X

Loh, T.C., S.W. Chong, H.L. Foo and F.L. Law, 2009. Effects on growth performance, faecal microflora and plasma cholesterol after supplementation of spray-dried metabolite to postweaning rats. Czech J. Anim. Sci., 54: 10-16.
Nguyen, T.D.T., H.J. Kang and M.S. Lee, 2007. Characterization of Lactobacillus plantarum $\mathrm{PH} 04$, a potential probiotic bacterium with cholesterollowering effects. Int. J. Food Microbiol., 113: 358-361. DOI: 10.1016/j.ijfoodmicro.2006.08.015

Niu, J., Y.J. Liu, L.X. Tian, K.S. Mai and Q.C. Zhou et al., 2007. Maize oil can replace fish oil in the diet of grouper postlarvae (Epinephelus coioides) without adversely affecting growth or fatty acid composition. Am. J. Agric. Biol. Sci., 2: 81-87. http://www.scipub.org/fulltext/AJAB/AJAB228187.pdf

Oliveira, R.P.S., A.C.R. Florence, R.C. Silva, P. Perego and A. Converti et al., 2009. Effect of different prebiotics on the fermentation kinetics, probiotic survival and fatty acids profiles in nonfat symbiotic fermented milk. Int. J. Food Microbiol., 128: 467-472. DOI: 10.1016/j.ijfoodmicro.2008.10.012

Pourahmad, M., A.S. Jahromy and M. Shojaei, 2009. Association of Mycoplasma pneumoniae infection with myocardial infarction. Am. J. Immunol., 5: 84-88. DOI: 10.3844/ajisp.2009.84.88

SanGiovanni, J.P. and E.Y. Chew, 2005. The role of omega-3 long-chain polyunsaturated fatty acids in health and disease of the retina. Prog. Retinal Eye Res., 24: 87-138. DOI: 10.1016/j.preteyeres.2004.06.002

Sindhu, S.C. and N. Khetarpaul, 2003. Effect of feeding probiotic fermented indigenous food mixture on serum cholesterol levels in mice. Nutr. Res., 23: $1071-1080$. DOI: $10.1016 / \mathrm{S} 0271-$ 5317(03)00087-3

Talon, R., D. Walter and M.C. Montel, 2000. Growth and effect of staphylococci and lactic acid bacteria on unsaturated free fatty acids. Meat Sci., 54: 41-47. DOI: 10.1016/S0309-1740(99)00068-6

Thanh, N.T., T.C. Loh, H.L. Foo, M. Hair-Bejo and B.K. Azhar, 2009. Effects of feeding metabolite combinations produced by $L$. plantarum on growth performance, faecal microbial population, small intestine villus height and faecal volatile fatty acids in broilers. Br. Poult. Sci., 50: 298-306. DOI: 10.1080/00071660902873947

Ting, A.S.Y., S.W. Mah and C.S. Tee, 2010. Identification of volatile metabolites from fungal endophytes with biocontrol potential towards Fusarium oxysporum F. sp. cubense Race 4. Am. J. Agric. Biol. Sci., 5: 177-182. DOI: 10.3844/ajabssp.2010.177.182 